\title{
Bougie through Murphy's Eye During Airway Exchange: A Near Miss
}

\author{
Vattipalli Sameera ${ }^{1}$ Konish Biswas ${ }^{2} \quad$ Girija P. Rath ${ }^{1}$ \\ 1Department of Neuroanaesthesiology and Critical Care, \\ Neurosciences Centre, All India Institute of Medical Sciences, \\ New Delhi, India \\ 2Department of Anaesthesiology, All India Institute of Medical

\begin{abstract}
Address for correspondence Girija Prasad Rath, MD, DM, Department of Neuroanaesthesiology and Critical Care, Neurosciences Centre, All India Institute of Medical Sciences, New Delhi 110029, India (e-mail: girijarath@yahoo.co.in).
\end{abstract} Sciences, Rishikesh, India

J Neuroanaesthesiol Crit Care 2021;8:136-138.

\author{
Abstract \\ Keywords \\ - endotracheal tube \\ exchange \\ - ETT introducer \\ (bougie) \\ - Murphy's eye \\ - complications
}

Endotracheal tube (ETT) exchange is a common procedure performed in the operating room and intensive care unit for the purpose of changing damaged or soiled ETT with appropriate one. The exchange procedure is performed over an airway exchange catheter or ETT introducer (bougie). We report an event during ETT exchange over bougie wherein the introducer exited through Murphy's eye. Here, we intend to re-emphasize the safety concerns pertaining to the use of bougie (with coude tip) as airway exchange conduit and enumerate the precautions to be taken during tube exchange.

\section{Introduction}

Endotracheal tube (ETT) exchange is a common procedure performed in the operating room (OR) and intensive care unit (ICU) for the purpose of changing damaged, soiled, or wrong-sized tube with the appropriate one. Tube exchange is performed over a conduit like airway exchange catheter (AEC) or endotracheal tube introducer (bougie). We report an event during ETT exchange over bougie wherein the introducer exited through Murphy's eye.

\section{Case Report}

A 61-year-old man with C3-C4 prolapsed intervertebral disc was taken up for anterior cervical discectomy and fusion. Endotracheal intubation with videolaryngoscope and manual inline stabilization (MILS) was planned as fiberoptic bronchoscope was unavailable for technical reasons. After induction of anesthesia, the trachea was intubated with $8.5 \mathrm{~mm}$ internal diameter (ID) cuffed endotracheal tube

Published online June 7, 2020
DOI https://doi.org/

$10.1055 / \mathrm{s}-0040-1710702$ ISSN 2348-0548.
(Portex, Smiths Medical, Minneapolis, MN, USA) and fixed at $22 \mathrm{~cm}$ at the lip. After intubation, persistent leak around the ETT was noticed. Cuff pressure monitor indicated steady decline in pressures after reinflation of the cuff. Due to suspicion of faulty/damaged cuff, ETT exchange over bougie (Portex single-use tracheal tube introducer, Coudé tip, $5.0 \mathrm{~mm}$ diameter, $60 \mathrm{~cm}$ length, angle $40^{\circ}$ ) was decided. The bougie was inserted till $23 \mathrm{~cm}$ at the lip. No resistance was encountered during bougie insertion, whereas significant resistance was felt when the damaged ETT was withdrawn over it; it was realized that the bougie exited through

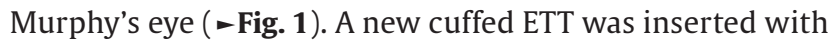
videolaryngoscopy and secured, and rest of the management proceeded uneventfully. There were no elevated airway pressures or hemodynamic fluctuations throughout the surgery. Tracheal suctioning at the end of the surgery did not reveal any blood-stained secretions. The patient was extubated and shifted to postanesthesia care unit. Postoperative chest X-ray and further course in the hospital were unremarkable. (c) 2020. Indian Society of Neuroanaesthesiology and Critical Care. This is an open access article published by Thieme under the terms of the Creative Commons Attribution-NonDerivative-NonCommercial-License, permitting copying and reproduction so long as the original work is given appropriate credit. Contents may not be used for commercial purposes, or adapted, remixed, transformed or built upon. (https://creativecommons.org/licenses/by-nc-nd/4.0/).

Thieme Medical and Scientific Publishers Pvt. Ltd. A-12, 2nd Floor, Sector 2, Noida-201301 UP, India 


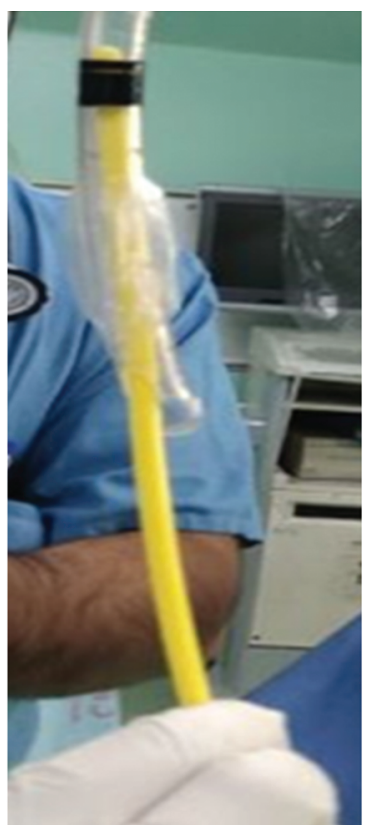

Fig. 1 Introducer coming out through Murphy's eye instead of the tip of the endotracheal tube while removing.

\section{Discussion}

ETT introducer is commonly used to facilitate tracheal intubation in case of difficult laryngoscopic view. The coude tip ( 35 to $40^{\circ}$ curved tip) has been designed for easy passage into the anteriorly placed laryngeal inlet and to prevent it from going too far down the airway, thereby reducing trauma. ${ }^{1}$ ETT introducer is also used for ETT exchange, preferred over AEC by some, as it is believed to be rigid enough to facilitate proper railroading. 2,3 As AEC was not readily available in the OR, ETT introducer (bougie) was used for tube exchange. Any device passed through ETT can exit through Murphy's eye instead of the tip. Exit of fiberoptic devices ${ }^{4}$ and curved tip catheters ${ }^{5}$ from Murphy's eye have been reported in the literature. Exit of AEC through a tear in a uninvent tube leading to failed exchange ${ }^{6}$ has also been reported, suggesting that conduit can exit through any potential opening. When bougie exits through Murphy's eye, the tip is naturally directed laterally, that is, toward the wall of the trachea. There is an increase in the combined cross-sectional area inside the tracheal lumen ( - Fig. 2). Being less malleable, the bougie might not negotiate its way through the space available in tracheal lumen unlike most suction catheters do. Pushing or manipulating it further in can potentially cause direct trauma to tracheal wall, even perforation. Pneumothorax during airway exchange over bougie has been reported. ${ }^{7}$ This, along with various other complications such as bronchial rupture ${ }^{8}$ and pharyngeal trauma ${ }^{9}$ led to serious concerns against using it for tube exchange. Moreover, length of bougie $(60-70 \mathrm{~cm})$ is less than the AECs available in the market $(80-100 \mathrm{~cm})$ can make it difficult to stabilize during exchange. ${ }^{10}$

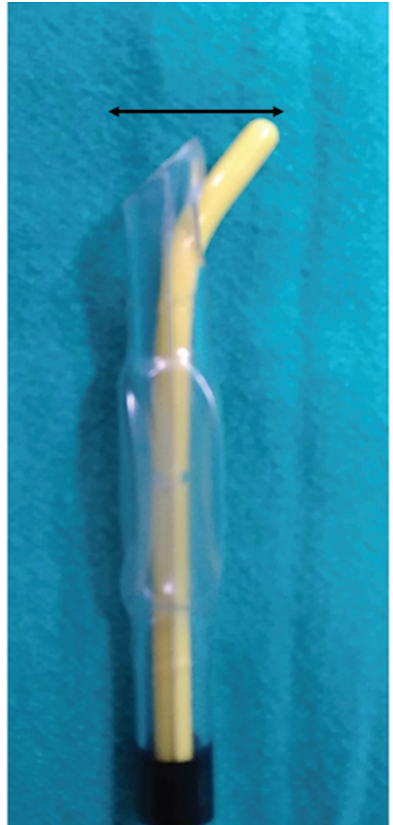

Fig. 2 Increased combined cross-sectional area when the tip of bougie exits through Murphy's eye. any further manipulation will direct the tip laterally toward the tracheal wall.

AECs are more flexible and soft-tipped, making airway exchange safer. Simultaneous oxygen insufflation can also be performed during exchange. However, bronchial lacerations and pneumothorax with ${ }^{11}$ or without ${ }^{12}$ evidence of tracheobronchial injury have been reported during tube exchange with AECs as well. Exit of AEC through Murphy's eye as the cause for failed tube exchange requiring reintubation has also been proposed. ${ }^{13}$

Here, we intend to emphasize the safety concerns pertaining to the use of bougie (with coude tip) as airway exchange conduit and enumerate the precautions to be taken during tube exchange. Being specifically designed for the purpose of tube exchange, AEC should be considered as the first choice. Using laryngoscopic guidance to negotiate the supraglottic/glottic structures and choosing a relatively larger sized AEC have been suggested to maximize the chances of successful tube change. ${ }^{14}$ AECs should not be inserted more than $24 \mathrm{~cm}$ from the lip. ${ }^{15}$ Highlighting the safe insertion depth by colored markers can be of help in preventing overinsertion. ${ }^{16}$ Fiberoptic bronchoscope, if passed alongside AEC, can help to visualize the tip and ensure safe exchange ${ }^{17}$ however, it is not always possible. Any conduit used for an exchange should never be forced when resistance is encountered. In case of doubt or difficulty, ETT should be removed along with the conduit and reintubation should be performed, instead of manipulating either of them. However, this procedure may not be free from complications such as injury to the tracheal wall due to increase in cross-sectional area of combined ETT with bougie inside Murphy's eye (-Fig. 2). Care must be taken with regard to the direction of coude tip. If it is toward the right of the patient during insertion of the bougie, it is more likely to exit through Murphy's eye than while facing anterior or slightly to the left. 


\section{Conclusion}

It should be remembered that any airway exchange conduit can exit through either of the two openings in ETT (tip/Murphy's eye) causing difficulty in exchange or injury. Despite the concerns with regard to increased flexibility, AECs are by large considered safe conduits to facilitate exchange. They need to be readily available for use in the OR and should always be preferred over bougie. Any resistance during the process of manipulation should be carefully handled with anticipation of possible problems, as discussed.

\section{Conflict of Interest}

None declared.

\section{References}

1 Hodzovic I, Wilkes AR, Latto IP. To shape or not to shapesimulated bougie-assisted difficult intubation in a manikin. Anaesthesia 2003;58(8):792-797

2 Umesh G, Sushma KS, Sindhupriya M, Swarnamba UN. Gum elastic bougie as a tube exchanger: modified technique. Indian J Anaesth 2015;59(12):827-829

3 Nekhendzy V, Simmonds PK. Rigid bronchoscope-assisted endotracheal intubation: yet another use of the gum elastic bougie. Anesth Analg 2004;98(2):545-547

4 Nichols KP, Zornow MH. A potential complication of fiberoptic intubation. Anesthesiology 1989;70(3):562-563

5 Kubota Y, Toyoda Y, Kubota H. A potential complication associated with a tracheal tube with a Murphy eye. Anaesthesia 1989;44(10):866-867

6 Eisenach JHMD, Barnes RDMD. Potential disaster in airway management: a misguided airway exchange catheter via a hole bitten into a univent endotracheal tube. Anesthesiology 2002;96(5):1266-1268

7 Kumar KR, Batra RK, Dhir R, Sharma SC. Inadvertent pneumothorax caused by intubating bougie. J Anaesthesiol Clin Pharmacol 2015;31(2):271-272

8 Sahin M, Anglade D, Buchberger M, Jankowski A, Albaladejo P, Ferretti GR. Case reports: iatrogenic bronchial rupture following the use of endotracheal tube introducers. Can J Anaesth 2012;59(10):963-967

9 Kadry M, Popat M. Pharyngeal wall perforation-an unusual complication of blind intubation with a gum elastic bougie. Anaesthesia 1999;54(4):404-405

10 El-Orbany M, Salem MR. The Eschmann tracheal tube introducer is not an airway exchange device. Anesth Analg 2004;99(4):1269-1270

11 de Almeida JP, Hajjar LA, Fukushima JT, Nakamura RE, Albertini $\mathrm{R}$, Galas FR. Bronchial injury and pneumothorax after reintubation using an airway exchange catheter. Braz J Anesthesiol 2013;63:107-109

12 Harris K, Chalhoub M, Maroun R, Elsayegh D. Endotracheal tube exchangers: should we look for safer alternatives? Heart Lung 2012;41(1):67-69

13 Nates JL, Berner DK. Mishaps with endotracheal tube exchangers in ICU: two case reports and review of the literature. The Internet J Emerg Intens Care Med 2000;5(1):1-5

14 Benumof JL. Airway exchange catheters: simple concept, potentially great danger. Anesthesiology 1999;91(2):342-344

15 Udomtecha D. Airway tube exchanger techniques in morbidly obese patients. Anesthesiol Res Pract 2012;2012:968642

16 Leeson S. The highlight technique: airway exchange catheters with a colored marking may improve safety of airway management. Anesth Analg 2011;112(2):481

17 Ayoub CM, Lteif AM, Rizk MS, Abu-Jalad NM, Hadi U, Baraka AS. Facilitation of passing the endotracheal tube over the flexible fiberoptic bronchoscope using a Cook airway exchange catheter. Anesthesiology 2002;96(6):1517-1518 